\title{
Preface to the Yale Edition
}

Europeans who settled in Australia from 1788 onwards soon decided that the local animals were inferior. The egg-laying platypus and echidna and the quirky marsupials were taken to be primitive mammals that had survived only because Australia was isolated from other continents. This thinking did not stop Australians from feeling pride in their wildlife, but it was tempered by a belief that the mammals, and to some extent all the animals, were backward. The birds fitted this picture by seeming to lack any aptitude for song. Australians were willing to think this way because it fitted the nation's status as a relatively small (by population) and parochial outpost of European culture to the south of Asia. Australia looked to Britain, and later the United States, for guidance about culture and foreign policy. There was a view that the best of everything came from the north. Not until the I970s did Australians become culturally self-confident, deciding that their film directors, actors, novelists and scientists were as good as any in the world.

I am mentioning this in a preface for Northern Hemisphere readers to emphasise why the finding that Australia gave the world its songbirds is so significant in Australia. It proved a surprise all over the world, of course, but in Australia it suits nationalistic narratives about discarded notions of cultural inferiority and northern assumptions of superiority. I make the most of this in the book when I talk about 'northern orthodoxy' stunting thinking about birds.

We live in exciting times for bird research, which means that interesting new work has appeared since this book came out in Australia in 
the middle of 20I4. Those who follow bird classification should know about two papers that attempt to show how all the world's bird orders fit together. The first, published in Science in 2014 by Erich Jarvis and colleagues, offers a new classificatory tree for the world's thirty-eight bird orders. In chapter seven I say we don't know where pigeons fit on the avian tree of life, but this paper places them on a third branch, just above waterfowl and landfowl, in the company of flamingos and another three orders.

The paper is based on forty-eight whole genomes of species from thirty-five bird orders, rather than on selected gene sequences, so we might hope it provides an accurate picture of relationships. I was excited when it came out, but my enthusiasm wavered early in 2015 when another paper appeared, in Nature, using different but also high-quality genetic sequencing, featuring an avian tree that is not the same, with, for example, pigeons in a different location. The tree produced by Jarvis looks a little more plausible, but the differences between these papers ensure that uncertainty lives on. What is important to my book is that both papers agree about a close relationship between perching birds and parrots. I described this relationship as looking very likely, but now it is beyond doubt.

Another paper in 2015, by Gerald Mayr, rejects earlier claims that fossils found in Europe and North America, dating back as much as 55 million years, represent early parrots. These fossils weren't easy to reconcile with all the evidence that parrots originated in the Southern Hemisphere, so it is pleasing to know the claims can be discounted.

A December 2015 paper saw Joel Cracraft revamp his bold theory that all of today's birds have Gondwanan origins because, he said, the giant Chicxulub meteorite, which smashed violently into Mexico 65 million years ago, obliterated birds everywhere else. With co-author Santiago Claramunt, Cracraft is now proposing that the only avian meteorite survivors were in South America. The paper doesn't provide new fossil or genetic evidence, and instead relies on establishing that the deeper branches of clades tend to be from South America. This 
is true of pigeons and falcons, for example, but to make the theory work Cracraft and Claramunt propose that New Zealand wrens started out in South America, and that ostrich ancestors did so as well, then spread north and west through Alaska (as part of Beringia). According to this hypothesis, birds had two pathways for spread around the world, one through North America and the other through Australia via Antarctica. Their paper is interesting but speculative, with a discussion containing statements prefaced by 'we hypothesize' and the like.

It will be interesting to see what future research brings.

\section{References}

Claramunt $S$ and Cracraft J (2015) A new time tree reveals Earth history's imprint on the evolution of modern birds, Science Advances i: eI50I005.

Jarvis ED, Mirarab S, Aberer AJ, et al. (20I4) Whole-genome analyses resolve early branches in the tree of life of modern birds, Science 346: 1320-3I.

Mayr G (20I5) A reassessment of Eocene parrotlike fossils indicates a previously undetected radiation of zygodactyl stem group representatives of passerines (Passeriformes), Zoologica Scripta 44: 587-602.

Prum RO, Berv JS, Dornburg A, et al. (2015) A comprehensive phylogeny of birds (Aves) using targeted next-generation DNA sequencing, Nature 526: 569-73. 
This page intentionally left blank 